\title{
Экономика
}

\author{
УДК 338.2; 65.011
}

\section{C.A. Братченко}

\section{ГЕНДЕРНЫЕ ИЗМЕНЕНИЯ В РУКОВОДСТВЕ КАК ФАКТОР ПОВЫШЕНИЯ КАЧЕСТВА КОРПОРАТИВНОГО И ГОСУДАРСТВЕННОГО УПРАВЛЕНИЯ}

Феномену возрастающей роли женщин в обществе, политике и бизнесе и, в частности, увеличению числа женщин-руководителей посвящено немало работ. Большинство исследователей связывают этот факт либо с особенностями так называемого женского стиля управления, либо с институциональным социальноэкономическим развитием. Представляется, что указанные факторы не в полной мере объясняют суть данного явления, являются достаточными, но не необходимыми причинами имеющими место изменений.

В работе показано, что изменение гендерного состава управленческого корпуса является в числе прочего закономерным следствием изменения условий и задач управленческой деятельности, на которые вынуждены реагировать и государство, общество, и бизнес, поскольку повышение доли женщин-руководителей положительно сказывается на результативности и эффективности управленческих решений, на качестве управления в целом. Показано также, что роль женщин в данном случае - не вытеснить мужчин из процесса управления и даже не достичь гендерного баланса, а лишь дополнить «мужской стиль» управления, сделать управление более разнообразным, отвечающим более сложным реалиям, а, значит, содействовать повышению качества государственного и корпоративного управления.

Ключевые слова: женщина-руководитель, корпоративное управление, государственное управление, качество управления, женский стиль управления, институциональные изменения, изменение условий и задач управления.

DOI: $10.35634 / 2412-9593-2019-29-6-719-729$

\section{1. Введение. Постановка проблемы}

Тематика женского равноправия обсуждается уже много десятилетий, и с течением времени круг вопросов расширяется. Если в начале XX в. проблемами являлись избирательные права и равный доступ к рабочим местам, то в настоящее время все больше говорится о месте женщин в обществе и в политике, в том числе в высших эшелонах власти.

Данные изменения достаточно широко отражены в литературе. Целый ряд исследований посвящен изучению феномена изменяющейся роли женщин в обществе, политике и бизнесе, в том числе увеличению числа женщин-руководителей. Большинство исследователей связывают последнее либо с особенностями так называемого женского стиля управления, либо с социально-экономическим и культурным развитием.

Представляется, что предложенные гипотезы не в полной мере объясняют суть и причины изучаемого феномена: почему женщины начали играть более значимую роль в управлении.

Объектом исследования в настоящей статье является феномен увеличения доли женщин среди высшего эшелона государственного и корпоративного управления, а непосредственным предметом изучения - характер и причины данного явления.

Гипотеза, выдвигаемая в данной работе: изменение гендерного состава управленческого корпуса является в числе прочего закономерным следствием изменения условий и задач управленческой деятельности, новых стратегических вызовов, на которые вынуждены реагировать и государство, общество, и бизнес. В новых условиях предоставление женщинам больших властных полномочий положительно сказывается на результативности и эффективности управления, на качестве управленческих решений.

На основе вышесказанного необходимо выявить:

- изменения целей и задач, стоящих перед органами государственного управления, компаниями и корпорациями в условиях новых стратегических вызовов нашего времени;

- каким образом, за счет каких факторов увеличение доли женщин в органах управления плодотворно влияет на достижение новых (изменившихся) целей и решение новых (изменившихся) задач, то есть на качество управления, повышает эффективность и результативность управления в данных изменившихся условиях; 
- каковы перспективы и границы увеличения доли женщин в высших органах государственного управления и в бизнесе, ожидают ли нас в будущем советы директоров или Кабинеты министров, полностью или почти полностью состоящие из женщин, и почему.

Методология настоящей работы относится к междисциплинарным исследованиям. Объект исследования настоящей статьи представляет интерес для целого ряда наук (социологии, политологии, психологии, экономики, менеджмента, истории, этнографии, исторической антропологии), и в каждой из них он достаточно хорошо изучен. Однако каждая наука смотрит на данный объект под своим специфическим углом зрения, с точки зрения целей данной конкретной науки, что в некотором смысле предопределяет выводы, к которым приходят исследователи. Данная работа представляет собой попытку сопоставить и систематизировать эти частные выводы, и в результате синтеза прийти к неким интегральным выводам.

\section{2. Фактология: изменение места и роли женщин в государственных и корпоративных органах управления}

История знает немало имен выдающихся женщин: Клеопатра, Екатерина Вторая, Индира Ганди и др. Мария Склодовская-Кюри вошла в историю науки как первооткрыватель радиоактивности, она была первой женщиной, получившей Нобелевскую премию, причем дважды.

Среди выдающихся предпринимательниц также немало женщин. Например, в 1739 г. Элиза Лукас Пинкни, с детства любившая ботанику, научилась выращивать и обрабатывать индиго, благодаря чему стала одной из первых успешных предпринимательниц Соединенных Штатов. В 1793 г. в деревне Дятьково Марья Мальцева заложила фабрику по производству стекла и посуды, так что по сей день Дятьковский хрустальный завод является градообразующим предприятием г. Дятьково. Однако это было скорее исключением, роль женщины в традиционном обществе сводилась к «трем К»Kinder, Kirche, Kuchen (дети, церковь, кухня).

Феномен востребованности женщин в высших эшелонах власти начал формироваться в конце XX в., когда все больше женщин стали занимать высокие посты в политике. Среди них стоит назвать премьер-министра Великобритании с 1979 по 1990 гг. Маргарет Тэтчер, «железную леди». Более 13 лет должность федерального канцлера Германии занимает Ангела Меркель.

Постепенно подобные факты перестают восприниматься как исключение и становятся вариантом нормы, а сфера женского лидерства постепенно расширяется, в том числе за счет областей, ранее для женщин совершенно нетипичных. Например, начиная с 2012 г. в течение нескольких лет министрами обороны Германии, Норвегии, Швеции и Нидерландов были женщины.

Аналогичные изменения происходят в управлении бизнесом. Например, в 2016 г. 24 \% компаний в странах Большой семерки руководили женщины [1. С. 29]. В том числе промышленными гигантами: Мэри Барра возглавляет крупнейшую американскую автомобильную корпорацию General Motors, Индра Нуйи - председатель совета директоров и CEО компании РеpsiCo, Мэрилин Хьюсон президент и СЕО военно-промышленной корпорации Lockheed Martin. Кристин Лагард в течение почти 8 лет возглавляет МВФ. Но это не сугубо западный феномен. На Филиппинах доля руководителей-женщин составляет $39 \%$, в Китае - 30 \% [1. С. 29].

Существенно, что доля высокопоставленных женщин продолжает увеличиваться. В 2000 г. во главе компаний из рейтинга Fortune Global 500 стояло лишь три женщины. Через 9 лет их количество увеличилось до 15, в 2012 г. - до 19 [2]. Тренд увеличения доли женщин в составе советов директоров за последнее десятилетие наблюдается не только в США, но и по всему миру ${ }^{1}$ [3. С. 52-53].

Включение женщин в советы директоров положительно сказывается на результатах деятельности, на стоимости компании [3. С. 52]. Так, В 2007 г. Catalyst обнаружила, что доход от акций компаний, в совете директоров которых было как минимум три женщины, составил 16,7 \%, в то время как у остальных организаций - в среднем 11,5 \% [2]. Изучение 21980 компаний из 91 страны мира показало, что те компании, у которых среди топ-менеджеров есть женщины, получают на 15 \% больше доходов, чем «сугубо мужские» [4]. На российских материалах была показана связь между долей женщин - исполнительных директоров в СД и рентабельностью активов [5. С. 362].

Поскольку сфера государственного управления имеет некоммерческий характер, получить количественные оценки положительного влияния на результативность и эффективность государствен-

\footnotetext{
${ }^{1}$ Ernst \& Young LLP (2015): Women on boards: global approaches to advancing diversity.
} 
ного управления гораздо сложнее, и нам неизвестны работы на эту тему. Обычно исследователи мыслят в рамках качественных категорий: «исключение представителей какого-либо гендера из процессов решения задач государственного управления, несомненно, ведет к росту рисков и снижению эффективности процессов принятия и реализации решений» [6. С. 222]. Соответственно, вовлечение женщин в сферу государственного управления, «если это происходит не за счет искусственных квот и путем насаждения политкорректности, а за счет снятия барьеров на пути талантливых работников, вне зависимости от пола» [6. С. 222], повышает качество государственного управления.

Текущая ситуация в России не во всем корреспондирует с общемировыми тенденциями. Согласно всемирно известному исследованию Grand Thornton «Женщины в бизнесе» наша страна лидирует по доле компаний, возглавляемых женщинами (47\% в 2017 г.), а вот в государственном управлении картина несколько другая. По данным Росстата, за 2016 г. доля женщин в Совете Федерации составила $16 \%$, среди заместителей федеральных министров - $13 \%$, среди губернаторов $-4,7 \%$. На март 2019 г. женщины составляли $20 \%$ заместителей председателя правительства, $9 \%$ министров и 2,3 \% глав субъектов Российской Федерации. На субфедеральном уровне действие патриархальных установок выражено еще более явно, что приводит к низкой доле женщин на руководящих должностях в регионах и муниципальных образованиях [7. С. 30].

\section{3. Обзор литературы}

\section{1. Женский стиль управления}

В значительной доли работ повышение доли женщин-руководителей в бизнесе и государственном управлении объясняется особенным, женским стилем управления [8-10].

В связи с этим возникает вопрос: что из себя представляет женский тип управления, чем он отличается от мужского, и в чем преимущества женского стиля управления по сравнению с мужским (если, конечно, таковые имеются).

В обширном исследовании, проведенном при поддержке фонда Макартуров, были выделены и проанализированы деловые качества успешных предпринимателей (вне зависимости от пола), а затем деловые качества были проранжированы отдельно для мужчин-предпринимателей и для женщинбизнесменов. Это позволило выявить как факторы успеха, не зависящие от пола, так и специфику «мужского» и «женского» стилей управления (см. табл. ниже).

Сравнительные индексы рейтинга качеств у мужчин и женщин предпринимателей $(\mathrm{N}=185)$

\begin{tabular}{|l|c|c|c|c|}
\hline \multicolumn{1}{|c|}{ Качества } & ИМ $^{1}$ & ИЖ $^{2}$ & РМ $^{3}$ & РЖ $^{4}$ \\
\hline Умение точно просчитывать ходы на несколько ходов вперед & 2,77 & 3,35 & 14 & 22 \\
\hline Умение рискнуть, поставить все «на карту» и выигрывать & 3,24 & 3,87 & 22 & 24 \\
\hline $\begin{array}{l}\text { Умение рационально распоряжаться вложенным капиталом и } \\
\text { контролировать его использование }\end{array}$ & 3,12 & 2,71 & 21 & 15 \\
\hline $\begin{array}{l}\text { Умение чувствовать себя свободными и извлекать выгоду в рамках } \\
\text { принятых ограничений и правил }\end{array}$ & 1,94 & 2,96 & 3 & 18 \\
\hline $\begin{array}{l}\text { Умение при необходимости играть «вне правил», извлекать выгоду из } \\
\text { неопределенных и нестандартных ситуаций }\end{array}$ & 2,91 & 3,51 & 19 & 23 \\
\hline Умение быстро переключаться с одного дела на другое & 2,90 & 2,48 & 18 & 10 \\
\hline $\begin{array}{l}\text { Умение длительно работать и концентрировать внимание в рамках одной } \\
\text { проблемы }\end{array}$ & 2,76 & 2,70 & 13 & 16 \\
\hline Умение противостоять давлению и нажиму, отстаивать свою позицию & 2,52 & 2,35 & 9 & 8 \\
\hline Умение понять и принять чужую точку зрения & 3,48 & 2,54 & 23 & 12 \\
\hline $\begin{array}{l}\text { Умение идти на компромисс, гибко вести переговоры, учитывать позицию } \\
\text { других сторон }\end{array}$ & 2,83 & 1,70 & 16 & 1 \\
\hline Умение при необходимости навязать другим свою позицию & 1,82 & 2,93 & 2 & 17 \\
\hline Постоянная готовность к изменениям, способность к нововведениям & 1,81 & 2,25 & 1 & 4 \\
\hline Трезвое отношение к новшествам, здоровый консерватизм & 2,66 & 2,35 & 12 & 7 \\
\hline
\end{tabular}




\begin{tabular}{|l|c|c|c|c|}
\hline \multicolumn{1}{|c|}{ Качества } & ИМ $^{1}$ & ИЖ $^{2}$ & РМ $^{3}$ & РЖ $^{4}$ \\
\hline $\begin{array}{l}\text { Умение эффективно использовать навыки, способности, знания других } \\
\text { людей в зависимости от ситуции }\end{array}$ & 2,00 & 2,29 & 4 & 6 \\
\hline Умение жить сегодняшним днем «здесь и сейчас» & 4,00 & 2,41 & 24 & 9 \\
\hline Умение строить деловые стратегии с учетом длительной перспективы & 3,00 & 2,67 & 20 & 14 \\
\hline Уверенность в себе и своей миссии & 2,46 & 2,12 & 8 & 2 \\
\hline Умение быстро делать выбор & 2,40 & 2,26 & 6 & 5 \\
\hline Умение действовать в ситуации конфликта и угрозы риска & 2,54 & 2,16 & 10 & 3 \\
\hline $\begin{array}{l}\text { Умение вовремя выйти из трудной ситуации конфликта, при } \\
\text { необходимости поменять партнеров }\end{array}$ & 2,81 & 3,03 & 15 & 19 \\
\hline Умение ставить цели, увлекать других людей & 2,24 & 2,51 & 5 & 11 \\
\hline Умение использовать чужие идеи для реализации собственных целей & 2,63 & 3,21 & 11 & 20 \\
\hline $\begin{array}{l}\text { Умение производить впечатление, налаживать и поддерживать } \\
\text { взаимоотношения с другими людьми }\end{array}$ & 2,42 & 2,55 & 7 & 13 \\
\hline Умение находить и создавать новые сферы деятельности или бизнеса & 2,85 & 3,22 & 17 & 21 \\
\hline $\begin{array}{l}\text { Умение прямо или косвенно влиять на высшие эшелоны власти } \\
\text { и политические решения }\end{array}$ & 4,72 & 4,98 & 25 & 25 \\
\hline
\end{tabular}

Источник: [11]

${ }^{1}$ ИМ - Индексы рейтинга качеств мужчины;

${ }^{2}$ ИЖ - Индексы рейтинга качеств женщины;

${ }^{3} \mathrm{PM}$ - № ранга - мужчины;

${ }^{4}$ РЖ - № ранга - женщины.

Выделим самые существенные факторы, отличающие успешных руководителей-мужчин и руководителей-женщин.

Для мужчины успех - это череда задач, которые он должен решить, и целей, которые ему нужно достигнуть. Соответственно, если цель по каким-то причинам не достигнута или задача не решена, то это воспринимается мужчиной-руководителем как личное поражение. В этой связи подчиненные для мужчины-руководителя - это в некотором смысле ресурс, который можно и должно использовать для достижения целей организации. С подчиненными обычно выстраиваются «нормальные» иерархические отношения. И одновременно это своего рода коммерческие отношения - за отлично выполенное задание полагается поощрение, за нерадивость и безответственность возможно (справедливо) применить наказание. Женщина-руководитель чаще всего воспринимает себя неотъемлемой частью коллектива. Для нее важно заинтересовать подчиненных, превратить задачи, стоящие перед организацией в общие цели рабочего коллектива и каждого сотрудника. Моральная поддержка подчиненных, их поощрение и мотивация - сильные стороны женского стиля управления $[12 ; 13]$.

Мужчинам важны положение и авторитет, которые дает им должность, они чаще используют властные полномочия. Для него важно чувствовать себя как формальным, так и неформальным лидером. Женское честолюбие не столь прямолинейно, женщина-руководитель зачастую не только позволяет, но и может поощрять лидерство других, сама при этом оставаясь «в тени», предпочитая роль «серого кардинала» [11]. Женщинам легче делегировать полномочия, чем мужчинам [9. С. 15].

На первый взгляд парадоксальные результаты были представлены в исследованиях [12; 14]: оказывается, женщины и с конкурентами пытаются выстраивать отношения сотрудничества и пытаются избегать конфронтации, силовых решений. У большей части женщин-руководителей вообще нет проблем с конкурентами. Однако, если задуматься, это вполне закономерно: во внешней среде женщина выстраивает отношения на тех же принципах, что и во внутренней.

Мужчина в большой степени сконцентрирован на достижении результата как такового, для женщины значимы детали и контекст («женщина имеет вкус к мелочам»), а также согласованность действий, что в итоге является важным фактором успеха при решении сложных, многокомпонентных и многокритериальных задач [11]. 
Мужчины легче решают стратегические задачи, их преимущества расположены в пространстве стратегии и анализа. Женщина, напротив, - весьма эффективный тактик, что дает ей определенные преимущества для достижения поставленных целей.

И женщины, и мужчины предпочитают принимать рациональные решения, однако для мужчины даже при принятии сложного решения обычно важно сделать экономические расчеты, понять, какие экономические выгоды он будет иметь завтра. В этом случае иногда упускаются из виду «второстепенные» факторы, которые могут оказаться решающими. Женщине легче по сравнению с мужчинами дается принятие интуитивных решений со многими переменными или даже неизвестными, при наличии нескольких критериев или в условиях неопределенности.

Мужчины более целеустремленные, успешнее решают одну или немногое число задач одновременно, женщины более рассредоточены, легче переключаются с одной задачи на другую, легче действуют в условиях мультизадачности.

Во взаимоотношениях с внешней средой женский стиль управления отличается большей гибкостью, ситуативностью, умением адаптироваться к сложившимся (в том числе и к изменяющимся. С.Б.) обстоятельствам [9. С. 14]. В частности, женщина готова перестроиться и наметить новую цель, еще не достигнув ранее намеченной, особенно, если изменились обстоятельства, мужчина более целеустремленен и обычно намечает и начинает двигаться к новой цели только после того, как решит ранее поставленную задачу.

Женщины по своей натуре менее склонны к риску, чем мужчины. Они дольше взвешивают «за» и «против» при принятии решения. Эту черту можно рассматривать и как преимущество, и как недостаток. Именно поэтому женский бизнес по сравнению с мужским обычно более стабилен. Однако одновременно это может быть фактором, приводящим к снижению финансовых результатов [11; 13]. В исследовании был выявлен весьма интересный факт: более рискованные стратегии выбирали те женщины-предприниматели, которые попадали в «старшую» возрастную группу и имели стаж менеджмента 15-20 лет. Более молодые менеджеры предпочитали не столь высокие, но более надежные прибыли. Желание не рисковать имело разнообразные интерпретационные модели, но суть их сводилась к простому факту: нельзя рисковать теми, кто рядом. Парадокс поклонниц риска состоял в том, что они придерживались той же точки зрения: «Ради тех, кто рядом, стоит рискнуть...». В целом меньшая амбициозность и нежелание достигать победы «любой ценой» позволяют действовать женщине в ситуации риска не менее эффективно, чем мужчине [11].

Для женщин, вовлеченных в государственное управление, наиболее значимыми чертами оказываются их умение принимать политические решения с учетом интересов всех социальных слоев населения, бороться за интересы малозащищенных групп, смягчать противоречия и предлагать эффективные решения и приемлемые для всех сторон компромиссы в ситуациях серьезных разногласий [15. C. 281].

В ряде исследований [11-13] было показано, что эффективный менеджмент, строго говоря, не является ни мужским, ни женским. Менеджер, кем бы он не был - мужчиной или женщиной - для того, чтобы быть успешным, должен обладать универсальными компетенциями руководителя. Женского или мужского стиля управления в чистом виде не существует, говорить о мужском или женском стиле управления корректно лишь в определенных рамках, как о некоторой специфике управления. При этом успешный менеджер, независимо от пола, должен уметь в разных ситуациях действовать по-разному - иногда «как мужчина», а иногда «как женщина». Если руководитель предпочитает опираться исключительно на «женские» или на «мужские» компетенции, то чаще всего он не может рассчитывать на успех [11].

Исходя из вышесказанного, женский стиль управления имеет свои преимущества, и поэтому женщины должны были быть вовлечены в управление всегда. Данный фактор статичен и не в состоянии объяснить динамику - почему растет доля женщин в высших эшелонах власти.

\section{2. Роль социально-институциональных изменений}

Ряд исследователей рассматривает феномен женщины-руководителя в социальноинституциональном контексте. Значительная часть этой группы работ строится на комбинации нескольких тезисов: роль женщины растет, доля женщин увеличивается, но гендерный дисбаланс еще существует, желательно, чтобы роль женщин продолжала расти и дисбаланс исчез, и наступило бы полное равноправие, правительства предпринимают меры по повышению участия женщин [16-18]. 
Целенаправленные усилия со стороны власти по увеличению гендерного равноправия, а также по увеличению доли женщин в управлении, действительно предпринимаются во многих странах и, в том числе в России. По этому поводу принят целый ряд международных ${ }^{2}$ и национальных ${ }^{3}$ документов. Одним из самых распространенных и эффективных методов решения данной проблемы считается квотирование [16;19].

В этой связи следует согласиться с мнением, высказанным бывшим министром по делам женщин Великобритании Марией Милер, что «продвижение женщин на высшие руководящие посты должно происходить не за счет искусственных квот, путем насаждения политкорректности, а за счет снятия барьеров на пути талантливых работников, вне зависимости от пола» [6. С. 222].

С другой стороны, сам факт целенаправленных усилий на международном и правительственном уровнях свидетельствует о наличии институциональных предпосылок для возрастания роли женщин в обществе и в управлении - государством, обществом или бизнесом. Как минимум это говорит о том, что лица, принимающие решения на уровне государств или надгосударственных организаций (изначально преимущественно мужчины):

- сами рассматривают женщин как коллег и готовы ради этого «потесниться» и разделить свои полномочия с другим полом;

- полагают участие женщин в управлении полезным и эффективным;

- полагают, что общество (коллектив) готово к подобным переменам и не воспримет предлагаемую новацию «в штыки».

Общество действительно меняется, в том числе институциональные установки относительно роли женщин в нем. Отношение к женщине-руководителю становится все более и более толерантным и положительным. Так, одна из крупнейших в мире фармацевтических компаний английская GlaxoSmithKline объявила о планах по увеличению доли женщин на руководящих должностях во всех регионах присутствия компании с 31 \% до $37 \%$ к 2022 г. ${ }^{4}$

Работ, в которых анализируется, за счет чего это происходит, не так много. Типичными являются несколько объяснений.

Успех женщины как руководителя зависит от той социальной и культурной (то есть институциональной. - С.Б.) среды, в которой формируется ее личность и деловое окружение [20. С. 103-104].

Соответственно, верно и обратное: поскольку разные институциональные среды отводят женщине разные роли, то при институциональном изменении среды роль женщины в обществе обычно несколько меняется.

Об определяющей роли институциональных факторов на примере постсоветского трансформационного периода очень ясно говорит И.Р. Чикалова: «С распадом СССР меры по поддержанию гендерной симметрии в органах представительной власти были упразднены, а структуры, обеспечивающие возможность совмещения женщинами материнской и профессиональной функций - подорванными. К началу 1990-х гг. парадоксальная задача состояла не в том, чтобы адаптировать идею равенства мужчин и женщин в общественном сознании, а в том, чтобы разрушить миф о достигнутом равенстве. Повторяемый в течение десятков лет тезис о «решѐнности женского вопроса в СССР» и равенстве женщины с мужчинами в нашей стране сыграл с общественным сознанием нации злую шутку - общество, освободившееся от пут тоталитарной идеологии, пребывало в уверенности, что дискриминации женщин в нашей стране нет. Тем не менее, когда в 1989 г. была отменена советская идея обязательного квотирования, участие женщин в представительных органах власти на всех уровнях - национальном, областном, городском, районном, сельском - резко снизилось» [21. С. 70-71].

При рассмотрении институциональных факторов во многих работах подчеркивается отрицательная институциональная роль (например, «к проблемам, ограничивающим участие женщин в управлении, следует отнести общественные стереотипы, противящиеся женскому лидерству» [9. С. 8]; «адекватному представительству женщин в политике и управлении РФ препятствуют социокультурные стереотипы» [10. С. 241]), что, безусловно, верно. Однако это отражает лишь одну - негативную - сторону

\footnotetext{
${ }^{2}$ Например, Конвенция о политических правах женщин, принятая Генеральной Ассамблеей ООН 20 декабря 1954 г.

${ }^{3}$ Например, Национальная стратегия действий в интересах женщин на 2017-2022 гг. (Распоряжение от 8 марта 2017 г. № 410-p).

${ }^{4}$ URL: https://pharmpersonal.ru/publs/news/gsk-planiruet-uvelichitj-dolju-zhenschin-rukovoditelej-do-37-k-2022godu.html
} 
феномена, при игнорировании положительного вклада институциональных факторов. Во многих работах отмечается рост роли женщин в управлении, но лишь в некоторых говорится, что данный рост стал возможен благодаря институциональным изменениям, например, потому, что общество стало менее патриархальным.

Лишь в небольшом числе работ предприняты попытки выделить конкретные институциональные факторы, определяющие место и роль женщины в обществе и, в том числе женщины-руководителя. Так, у У. Батцэрэн отмечается зависимость восприятия женщины-политика от среды - городской (более модернизированной, индустриальной) или сельской (более традиционной) [15. С. 278], Н. Капур выделяет в качестве значимых культурные и религиозные факторы, а также уровень экономического развития [22. Р. 65].

Ю.Н. Бодина связывает изменение положения женщины с институциональными изменениями при переходе от традиционного аграрного общества, когда «мужской пол был хозяином земли и кормильцем, а ... земля давалась по числу мужских душ в семье» [20. С. 104] к индустриальному, когда женщина становится экономически независимой, что приводит к появлению не только пролетариев и интеллигентов, но и «пролетарок и интеллигенток», которые имеют разные интересы: «Пролетарки хотели облегчения условий труда, увеличения заработной платы, а интеллигентки добивались разрешения в участии решения политических проблем» [20. С. 104].

А.А. Козырев и Д.А. Горячева связывают гендерные сдвиги в управленческой сфере (прежде всего в государственном управлении) с постмодернизмом, размывающем всякие границы, в том числе и гендерные установки: активно развивается феминизм, представительницы которого активно желают реализовываться во всех жизненных сферах, в том числе «традиционно мужских». «Эти женщины хотят не только быть экономически независимыми, но и принимать участие в управлении страной» [23. С. 9-11].

Таким образом, изменение места и роли женщины в обществе связано с изменением институциональных условий, в результате которого женщина все в более активно осваивает мужские роли, а общество становится более толерантным и воспринимает данные изменения как норму. Данные изменения предоставляют женщине возможность играть иную роль в обществе, то есть, выражаясь языком математики, формируют лишь достаточные условия, которые отнюдь не являются необходимыми.

Для того чтобы произошли гендерные сдвиги в сфере управления, должны иметься необходимые условия, то есть должна появиться потребность в женщинах-руководителях как в бизнесе, так и в государственном управлении. Нам неизвестны работы, анализирующие формирование этих необходимых условий.

\section{4. Результаты и обсуждение}

\section{1. Изменение задач и условий управления в контексте новых стратегических вызовов}

Наш мир непрерывно меняется, но в последнее время эти изменения происходят со все возрастающей скоростью. Сейчас даже сложно представить, что в первой половине XX в. разработка новой стратегии компании занимала порядка 16 лет, еще порядка 10 лет уходило на внедрение стратегии и соответствующую перестройку компании, далеко не все компании смогли пройти этот трудный путь до конца, но те, которые прошли, оставались ведущими в своих отраслях в течение многих лет и десятилетий [24]. Тем не менее в настоящее время можно с уверенностью сказать следующее:

- скорость изменения среды возросла и продолжает расти;

- мир становится все более взаимозависимым, гиперсвязанным, когда действия «на одном конце земного шара» практически немедленно оказывают влияние на положение дел на другом континенте, будь то политические или экономические события;

- если раньше среда менялась более инерционно и ее изменения можно было в какой-то степени спрогнозировать, в современных условиях гиперсвязанного мира изменения среды чаще характеризуются как волатильные. Степень неопределенности внешней среды возрастает;

- в этих условиях управление объектом (компанией, государством) должно соответствовать изменениям среды (то есть быть реактивным), а для успеха управления желательно, чтобы эти изменения были проактивными [25. С. 64]. Как метко отметил Р. Грант: «Единственным устойчивым конкурентным преимуществом (в том числе для государств, на международной арене. - С.Б.) является способность создавать новые конкурентные преимущества» [26]; 
- усиление конкуренции требует от компаний все более профессионального управления, все более целенаправленных усилий по повышению операционной эффективности компании. Именно поэтому все большее применение получает процессное управление, управление на основе проектов, структура компаний становится все более горизонтальной, и т. п.;

- переход от ненасыщенного «рынка продавца» к насыщенному «рынку покупателя» ставит «во главу угла» задачу привлечения покупателя, поиск индивидуального подхода к потребителю, переход к производству максимально кастомизированных товаров и услуг;

- аналогичные изменения происходят и в сфере государственного управления, когда на первый план, например, выходит степень удовлетворения потребителя качеством оказываемых гражданам государственных услуг [27. С. 58-60].

\section{2. Востребованность женского стиля управления в условиях новых стратегических} вызиовов

1. Современные организационные структуры более «плоские», с меньшим числом уровней иерархии, по сравнению с теми, которые наблюдались еще 20-30 лет назад. Это неслучайно. J.O'Shaughnessy еще в 1976 г. писал: чем более неопределенна работа, которая должна быть выполнена, тем площе организационная структура... Плоская структура лучше для горизонтальной коммуникации, которая необходима, чтобы достичь координации индивидуальных усилий в условиях неопределенности» [28]. Однако уменьшение уровней иерархии в организации при том же числе сотрудников приводит к увеличению числа подчиненных, приходящихся на одного руководителя. В данных обстоятельствах в структуре ответственности руководителя уменьшается доля сугубо рациональных решений, но одновременно возрастает число задач, которые приходится одновременно координировать, возрастает роль согласований и взаимодействия с подчиненными. А мультизадачность, педантичные согласования и социальная взаимодействие - это как раз те виды работ, с которыми успешно справляется женщина.

2. Одной из самых эффективных современных организационных структур является матричная структура, которая предполагает нарушение принципа единоначалия - когда у сотрудника может быть одновременно несколько руководителей (которые, случается, могут давать противоречащие друг другу задания и указания). В этой ситуации необходимым рабочим качеством становится не только сугубо дипломатические качества, а также сохранение в этих условиях доброжелательных неконфликтных рабочих отношений, умение согласовывать разнонаправленные рабочие процессы, находить оптимальное решение в условиях многокритериальности и аргументировать его перед руководителями. А умение работать в условиях мультизадачности и успешно превращать противоречивые и даже конкурентные отношения в отношения сотрудничества, решать задачи «на согласование» обычно легче дается женщине.

3. Необходимость постоянных изменений - как в связи с адаптацией к изменяющейся внешней среде, так и в связи с необходимостью осуществлять регулярные инновации и, значит, создавать условия для успешного инновационного развития [29. С. 105].

Женщина как хранительница рода (численность популяции в большей степени зависит от числа женских особей), более консервативна по сравнению с мужчиной, который по своей природе является бесстрашным инноватором. Поэтому инициативно-инновативную функцию в организации обычно лучше исполняет мужчина.

Инновации зачастую сопряжены с риском. Как было показано выше, принятие рискованных решений женщинами имеет свои особенности, и в данном вопросе мужской и женский подходы к риску могут удачно дополнять друг друга.

Однако хорошо известно, что внедрение инноваций часто вызывает сопротивление сотрудников, и здесь опять оказываются востребованными женские качества успешного сотрудничества, согласования и консенсуса.

О том, что инновационная активность компании зависит от типа ее корпоративной культуры и личностных качеств руководителя, известно давно, еще в конце прошлого века [30; 31]. Так, авторитарный стиль подавляет инновации, а атмосфера наставничества, взаимопомощи и сотрудничества, хорошая вертикальная коммуникация напротив раскрепощает проявление инициативы [32]. Рассматривая данные особенности корпоративной культуры через призму гендерных особенностей стилей управления, получается, что «женский стиль управления» может содействовать повышению инновационной активности. 
4. Усиление конкуренции приводит к увеличению требований к «прочности»компании, к необходимости развивать сотрудниество и кооперацию внутри компании [33. С. 98-99], с чем, как уже отмечалось ранее, прекрасно справляется женщина.

5. В условиях изменяющейся среды бывает так, что «лошадей приходится менять на переправе»: например, еще год назад решение А казалось самым оптимальным, а сейчас приходится его адаптировать или даже полностью отказываться от его реализации вследствие произошедших изменений во внешней среде. Мужчина такую ситуацию часто воспринимает как ошибочно принятое решение (и как следствие - что эту ошибку теперь нужно признавать, что наносит ущерб его авторитету). Между тем в исходных условиях принятое решение действительно могло быть самым эффективным, и в то время никто не мог знать, что ситуация изменится именно таким образом. Женщина обычно воспринимает такое развитие событий без болезненного акцента, и гораздо легче модифицирует стратегию, воспринимая это не как ошибку, а как естественное развитие, с которым она сталкивается ежедневно: методы, используемые при воспитании детей, быстро теряют свою эффективность по мере роста детей, их взросления и развития, и каждый раз нужно придумывать нечто новое, адекватное текущему уровню развития ребенка. Женщина легче понимает и принимает, что это не стратегия была неправильной, это условия изменились.

6. В связи с ростом волатильности и неопределенности внешней среды как в менеджменте, так и в государственном управлении возрастает доля нерациональных решений, принимаемых в условиях неопределенности и недостатка информации. В данных условиях «женские» решения, опирающиеся не только на точные расчеты, но и на интуицию, оказываются все более востребованы.

\section{3. Границы востребованности женщин в управлении}

Однако вышесказанное не означает, что данная тенденция может привести к полному замещению мужчин женщинами в советах директоров или иных высоких кабинетах власти, в том числе в государственном управлении. Роль женщин в данном процессе - не вытеснить мужчин из процесса управления, как мечтают феминистки, и даже не достичь гендерного баланса, а лишь дополнить «мужской стиль» управления, сделать управление более разнообразным, отвечающим все более сложным реалиям, а, значит, более гибким и более эффективным.

\section{5. Выводы}

Таким образом, увеличение доли женщин в высшем эшелоне власти (как в бизнесе, так и в государственном управлении) в последние годы не является случайным. Причины данных изменений связаны не только с институциональными подвижками (которые в данном случае выступают достаточным условием вышеуказанного роста), но, прежде всего, с изменениями задач и условий управленческой деятельности. Женский стиль управления оказывается востребованным (что означает наличие необходимого условия), поскольку привлечение некоторой доли женщин в управление повышает качество управления.

\section{СПИСОК ЛИТЕРАТУРЫ}

1. Baxter J.C. Women in leadership roles: a USA perspective // Педагогическое образование в России. 2018. № 1. C. 29-30.

2. Елкина В. Как женщины-руководители влияют на бизнес? URL: https://rb.ru/story/women-in-leadership/

3. Кокорева М.С., Степанова А.Н., Карноухова Е.В. Чего мы не знаем о структуре собственности крупнейших компаний США? // Экономическая политика. 2016. № 6. С. 36-59.

4. Noland M., Moran T., Kotschwar B. Is Gender Diversity Profitable? Evidence from a Global Survey // Peterson Institute for International Economics. Working Paper 16-3. February 2016. URL: https://piie.com/system/files/ documents/wp16-3.pdf

5. Березинец И.В., Гаранина Т.А., Ильина Ю.Б. Социальный капитал женщин - членов советов директоров и финансовая результативность компании: эмпирическое исследование // Российский журнал менеджмента. 2018. № 3. C. 337-370.

6. Дрогайцева Е.А. Проблема гендерных стереотипов и половой дифференциации в сфере управления // Научные труды Северо-западного института управления. 2016. № 2. С. 216-223.

7. Попова О.В. Гендерные аспекты политической карьеры российской субфедеральной элиты: мнения экспертов // Женщина в российском обществе. 2013. № 3. С. 21-30. 
8. Котоманова О.В. Проблема стилей, мотивации и участия в управлении мужчин и женщин // Вестн. Бурятского гос. ун-та. 2015. № 5. С. 91-95.

9. Смирнова Е.Д. Стиль управления женщин-руководителей в условиях трансформации российского общества: социологический анализ: автореферат. Пенза: Пензенский гос. ун-т. 2008. 22 с.

10. Цветкова Н.А. Женщины в системе государственного управления и политике России / Развитие российской системы государственного управления: реалии современности, тенденции, перспективы: сб. науч. тр. II междунар. науч.-практ. конф. М.: РАНХиГС. 2017. С. 240-242.

11. Чирикова А.Е. Женщина-руководитель во власти и бизнесе: социально-психологический портрет // Политическая экспертиза. Политэкс. 2011. Т. 7, № 1. С. 142-162.

12. Чирикова А.Е. Женщина во главе фирмы. М.: Институт социологии РАН. 1998. 358 с.

13. Поздняков В.П., Титова О.И. Отношение предпринимателей к конкуренции: гендерные различия // Знание. Понимание. Умение. 2014. № 3. С. 197-206.

14. Уткина Н.Ю. Объективные и субъективные факторы развития женского предпринимательства в России // Женщина в российском обществе. 2017. № 1. С. 17-28.

15. Батцэрэн У. Участие женщин в работе Великого государственного хурала Монголии и некоторые вопросы формирования политического имиджа // Вестн. Бурятского научного центра Сибирского отделения Российской академии наук. 2015. №1. С. 275-283.

16. Невежина М.В. Гендерная дискриминация в сфере труда: опыт борьбы на международном уровне // Журнал зарубежного законодательства и сравнительного правоведения. 2018. № 3. С. 187-193.

17. Халилова Д.А. Активизация роли женщин в государственном управлении современной России // Социология власти. 2012. № 3. С. 222-225.

18. Ялялиева Т.В. Вариативность эффективности экономики государственного сектора от степени участия женщин в управлении // Инновационные технологии управления и права. 2013. № 1-2. С. 59-62.

19. Штылева М.В. Реализация политики гендерного равенства в странах Северной Европы // Женщина в российском обществе. 2012. № 1. С. 75.

20. Бодина Ю.Н. Вовлечение женщин в руководство экономикой и управление народным хозяйством // Актуальные проблемы гуманитарных и естественных наук. 2009. №11. С. 103-105.

21. Чикалова И.Р. Женщины в структурах властной иерархии Беларуси (1991-2012) // Инновационные технологии управления и права. 2013. № 1-2. С. 70-74.

22. Kapoor N. Women in the Duma: why post-soviet Russia has low female representation? A view from India // CpaBнительная политика. 2016. № 2. С. 59-72.

23. Козырев А.А., Горячева Д.А. Ценностные ориентации государственных служащих: гендерный аспект // Управленческое консультирование. 2015. № 9. С. 8-19.

24. Chandler A.D. Jr. Strategy and Structure: Chapters in the History of the American Industrial Enterprise. Cambridge, USA: MIT Press. 1962.

25. Братченко С.А. «Сценарный менеджмент»: связь стратегии и тактики // Управленческие науки. 2016. № 4. C. $62-67$.

26. Grant R.M. Contemporary Strategy Analysis. Chichester, UK: John Wiley and Sons. 2015.

27. Братченко C.A. К вопросу о понятии качества государственного управления // Вестн. Института экономики PAH. 2019. № 1. C. 57-72.

28. O’Shaughnessy J. Patterns of Business Organization. Oxford, UK: Routledge. 2013.

29. Шамаева Н.П. Проблемы формирования кластеров на основе кооперации промышленных предприятий с научными организациями и образовательными учреждениями // Вестн. Удм. ун-та. Сер. Экономика и право. 2013. Вып. 2. С. 105-112.

30. Janis I. Groupthink (2nd ed.) Boston: Houghton Mifflin, 1982.

31. Nemeth C.J. Managing Innovation: When Less is More // California Management Review. 1997. 40(1).

32. Первакова Е.Е. Корпоративная культура как фактор роста инновационной активности персонала организации // Вестн. Удм. ун-та. Сер. Экономика и право. 2014. Вып. 2. С. 87-91.

33. Шамаева Н.П. Промышленная кооперация как фактор экономического развития // Вестн. Удм. ун-та. Сер. Экономика и право. 2014. Вып. 1. С. 98-108.

Поступила в редакцию 13.08.2019

Братченко Светлана Анатольевна, кандидат экономических наук, старший научный сотрудник

Институт экономики Российской академии наук

117218, Россия, г. Москва, Нахимовский проспект, 32

E-mail: svetlana.bratchenko@gmail.com 


\section{S.A. Bratchenko}

\section{GENDER SHIFTS IN MANAGEMENT BODIES AS A FACTOR OF INCREASING THE QUALITY OF CORPORATE AND PUBLIC GOVERNANCE}

DOI: 10.35634/2412-9593-2019-29-6-719-729

A lot of works is devoted to the phenomenon of the increasing role of women in society, politics and business, and of increasing the number of women leaders in particular. The most of the researchers attribute this fact either to the features of the so-called female management style or to institutional socio-economic development. The above-mentioned factors seem to not fully explain the essence of this phenomenon; they are sufficient, but not necessary reasons of occurring changes.

This paper shows that gender shifts in management and governance corps is, among others, a natural consequence of changes in the conditions and objectives of management, which are forced to respond both the state, and society and business. Increasing the women leaders share has a positive impact on the effectiveness and efficiency of management decisions, on the quality of governance in general.

It is also shown that the role of women in this case is not to oust men from top management, and not even to achieve a gender balance, but only to complement and enrich a "masculine style" of management. That makes the management more divers and responding to increasingly complex realities, and so it promotes the quality of public and corporate governance.

Keywords: woman leader, corporate management, governance, management and governance quality, female management style, institutional change, changes in the conditions and objectives of management.

Bratchenko S.A., Candidate of Economics, Senior Researcher Institute of Economics of Russian Academy of Sciences

Nakhimovsky pr., 32, Moscow, Russia, 117218

E-mail: svetlana.bratchenko@gmail.com 